\title{
Extensão universitária no enfrentamento da Covid-19: a universidade e o (re)configurar de projetos e ações
}

\section{University extension in coping with Covid-19: the university and the (re)configuration of projects and actions}

\author{
Marcelo Calderari Miguel ${ }^{1}$, Rogério Zanon da Silveira², Maria Lúcia Kopernick Del Maestro ${ }^{3}$ \\ 1 Instituto Histórico e Geográfico do Espírito Santo - IHGES; Associação Nacional de Pesquisa e Pós-Graduação em Psicologia - ANPEPP; Universidade \\ Federal do Espírito Santo (Ufes), Vitória, Espírito Santo, Brasil. ORCID: https://orcid.org/0000-0002-7876-9392 \\ 2 Universidade Federal do Espírito Santo (Ufes), Vitória, Espírito Santo, Brasil. ORCID: https://orcid.org/0000-0002-1410-2767 \\ 3 Universidade Federal do Espírito Santo (Ufes), Vitória, Espírito Santo, Brasil. ORCID: https://orcid.org/0000-0001-5687-8697
}

Autor para correspondência/Mail to: Maria Lúcia Kopernick Del Maestro, kopernick.kopernick@gmail.com

Recebido/Submitted: 29 de agosto de 2020; Aceito/Approved: 22 de dezembro de 2020

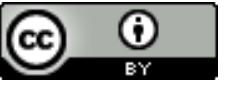

Copyright (c) 2021 Miguel, Silveira \& Del Maestro. Todo o conteúdo da Revista (incluindo-se instruções, política editorial e modelos) está sob uma licença Creative Commons Atribuição 4.0 Internacional. Ao serem publicados por esta Revista, os artigos são de livre uso em ambientes educacionais, de pesquisa e não comerciais, com atribuição de autoria obrigatória. Mais informações em http://revistas.ufpr.br/atoz/about/submissions\#copyrightNotice.

\begin{abstract}
Resumo
Introdução: a extensão universitária funciona com a comunicação de conhecimento. Nessa esfera está a questão de como aprender, empreender e conectar o conhecimento produzido diante das novas ou tradicionais interações que unem o ensino, as tecnologias da informação e a pesquisa universitária. Problema de pesquisa: quais são as ações extensionistas que a pandemia provoca na Universidade? Objetivo: identificar e analisar ações e projetos de enfrentamento à pandemia, exercendo atividade extensionista ao desenvolvimento da Responsabilidade Social Universitária, em uma universidade pública do estado do Espírito Santo. Metodologia: este estudo, cujo acervo bibliográfico documental desempenha autoridade necessária para a exposição do trabalho, tem cunho exploratório, descritivo, de corte transversal e se apoia em uma abordagem qualitativa de pesquisa. A extensão da Universidade Federal do Espírito Santo apresenta análise de conteúdo que situa as ações e os serviços direcionados à sociedade - essa categorização atua para delinear ações e projetos que têm como eixo central o Sars-Cov-2. Resultados: evidencia a estruturação de programas e projetos de extensão com a finalidade de preparar o agir social. Conclusão: sugere o avanço da temática de enfrentamento ao surto da doença, causada pelo novo coronavírus, aproximando o desenvolvimento da responsabilidade social universitária de ações possíveis e viáveis à área da ciência da informação.
\end{abstract}

Palavras-chave: Ciência da Informação; Responsabilidade Social; Inclusão Social; Extensão Universitária.

\begin{abstract}
Introduction: The university extension works with communication knowledge. In this sphere is the question of how to learn, undertake and connect the knowledge produced face of new or traditional interactions that unite teaching, information technologies and university research. Research problem: What are the extension actions that the pandemic causes at the university? Objective: To identify and analyze actions and projects to fight the pandemic, exercising an extension activity to the development of University Social Responsibility in a public university at Espírito Santo State, Brazil. Method: this study, whose bibliographic documental collection performs the necessary authority for the work exhibition, and has an exploratory, descriptive, cross-sectional nature and is supported by a qualitative research approach. The Universidade Federal do Espírito Santo extension presents a content analysis that situates actions and services directed to the society - this categorization acts to outline actions and projects that have the central axis of Sars-Cov-2. Results: it shows the structuring of extension programs and projects to prepare social action. Conclusions: it suggests advancing the theme of coping with the outbreak of the disease, caused by the new coronavirus, bringing the development of university social responsibility closer to possible and viable actions in the information science area.
\end{abstract}

Keywords: Information Science; Social Responsibility; Social Inclusion; University Extension.

\section{PRÁTICAS EXTENSIONISTAS E O CORONAVÍRUS: UM CONTEXTO QUE EXIGE RESPON- SABILIDADE E EMPATIA}

"A pandemia chegou - inesperada e impositiva - com potencial de atingir a TODOS, trazendo medo e insegurança aos que necessitam de cuidados e aos que prestam o cuidado. Muitas reflexões, muitas frases de efeito, entretanto, o momento requer ação! E agora?" (Madruga, 2020, p. 3). Assim a doutora em Epidemiologia, Samanta Madruga, abre o vigésimo quinto volume editorial (abril de 2020) na revista 'Expressa Extensão' da Universidade Federal de Pelotas - UFPel. Nesse cenário de incertezas, a pesquisadora questiona:

Quem está "preparado" para lidar com o caos? Quem vai usar máscara, não para si, mas para proteger o próximo? O desconhecido? Quem colocará seu juramento profissional embaixo do braço e encarar? Quem vai abrir mão da convivência, do abraço, do cheiro, para proteção dos demais? Quem vai conseguir se dedicar a serviço da humanidade, de verdade, e ofertar o cuidado incondicional? Quem? Essa pandemia, infelizmente, acaba por deixar mais evidente que o direito à saúde do brasileiro hoje, se choca frontalmente com valores pessoais em detrimento dos coletivos, se choca com o negócio, com o interesse, com a mídia e, com a política. Há quem diga que após a pandemia viveremos em um 
mundo melhor, é confortante acreditar nisso! Mas é frustrante pensar que será para quem sobreviver! Então... Estamos expostos a uma situação em que TODOS, sem exceção, têm um papel a cumprir, e isso é a grande prova, TODOS seremos responsáveis pelo desfecho final! Faça sua parte! (Madruga, 2020, p. 3).

Desse modo, é preciso entender que "nós, os cidadãos de bem, que cumprimos a lei, somos todos, em menor ou maior escala, igualmente responsáveis pelo bem e pelo mal que aí estão. Temos de responder por isso. Cada um responde como lhe cabe" (Thiry-Cherques, 2020, p. 47). Isso expressa uma pauta da frágil existência humana não sucumbir e zelar pela comunidade.

Sabe-se que as mazelas sociais, as calamidades e o estado de epidemias são dores para o Moderno Profissional da Informação (MPI) - amenizar esse cenário é tarefa de todos nós. Frente a uma ótica psicanalítica lacaniana, há de se reconhecer que "por nossa posição de sujeito, somos sempre responsáveis" (Lacan, 1966, p. 858).

Destarte, o pontuar do atual cenário é recuperado no olhar de Guareschi (2008, p. 6):

Assumimos aqui o Ser Humano como sujeito de relações, não como algo pronto, mas como em contínua construção. Ser humano significa, de fato, tornar-se humano, conquistar-se. A subjetividade humana é o resultado de milhões de relações. Recortamos, do universo dos milhares e milhões de relações que estabelecemos, parcelas específicas, diferenciadas e, com isso, construímos nossa subjetividade. Por isso mesmo, somos absolutamente singulares, únicos, irrepetíveis, pessoais (pessoa $=$ relação). Somos como que o ancoradouro de milhões de experiências, naus dispersas num imenso universo que um dia aportaram em nosso pequeno porto [...]. E na medida em que somos conscientes e livres, somos responsáveis.

Diante dessa prefalada responsabilidade, acolhem-se a Universidade Federal do Espírito Santo (Ufes), Instituto Superior de Educação (ISE) com o escopo de apontar algumas dimensões extensionistas que vêm se consolidando na universidade (em termo de quantidade de ações e projetos) envolvendo docentes, técnico-administrativos, discentes e a comunidade acerca da Corona Virus Disease (Covid-19). Tem-se em pauta um novo cenário (pandemia) que situa um caminho de transformação: novas atitudes, apreensões, inovações e um papel de responsabilidade social para a extensão universitária, visando à produção de conhecimentos e à interlocução do ensino e da pesquisa, na direção de processos de formação e informação.

Felipe e Gomes (2014) reportam que universidade possui a um espaço de excelência: ensino, pesquisa e extensão; e, dentre esses, a extensão é a mais recente e a que carece de investigações, visto que não há equiparação com as demais funções. Silva e Deboçã (2018), nessa mesma linha de pensamento, argumentam que a prática extensionista induz os indivíduos a atuarem eticamente na sociedade, por meio de um processo educacional participativo, político e crítico.

Assim sendo questiona-se: quais são as ações extensionistas que a pandemia provoca no comportamento universitário? O que pode ser enfatizado? Até que ponto os acadêmicos, isolados, teriam condições de participar de programas e projetos de relevância social e comunitária? Com o intuito de estudar a interligação da produção de conhecimento ocorrida na Universidade e a transferência dessa informação para a sociedade, por meio da extensão universitária, este estudo busca responder à seguinte pergunta: quais são os atuais projetos de extensão que a Universidade Federal do Espírito Santo (Ufes) tem direcionado ao combate da pandemia do novo coronavírus?

Este estudo, portanto, tem como objeto de pesquisa a Ufes e busca identificar ações e projetos de enfrentamento à pandemia, abordando temas de especial relevância como o do papel da atividade extensionista no desenvolvimento da Responsabilidade Social Universitária. O papel da universidade, é claro, sua missão, é notória: gerar, por meio do ensino, da pesquisa e da extensão, avanços científicos, tecnológicos, educacionais, culturais e sociais, "transferindo e socializando conhecimentos e inovações que contribuam para a formação do cidadão, visando ao desenvolvimento sustentável no âmbito regional, nacional e internacional" (Universidade Federal do Espírito Santo. Pró-reitoria de Extensão, 2020a, p. 1).

As atividades de extensão têm configurado um espaço para a construção de saberes e para a produção acadêmica, apresentando resultados expressivos. Tais ações envolvendo essa temática afirmam, por intermédio da produção e aplicação do conhecimento, o desenvolvimento de programas, projetos, cursos e oficinas, que promovem a interação acadêmica com a sociedade.

\section{RESPONSABILIDADE SOCIAL UNIVERSITÁRIA PARA O ENFRENTAMENTO DA PANDEMIA COVID-19}

A extensão universitária apoia-se no tripé ensino, pesquisa e extensão. Para Cristofoletti e Serafim (2020), isso alinha os objetivos institucionais de compromisso social da Universidade com o campo de teorização. Já Gattai e Bernardes (2013, p. 64) concluem que a universidade "atua na realidade social como sujeito, contribuindo para a transformação dela e, a seguir, produz conhecimento científico sobre esse processo". 
Chaui (2001, p. 35) alerta: a "universidade é uma instituição social" e, em razão disso, acaba por refletir as especificidades da sociedade em que está inserida; assim, a pesquisadora complementa: universidade não é uma "[...] realidade separada, e sim uma expressão historicamente determinada de uma sociedade determinada".

Jambeiro (1999, p. 50) cita que a universidade reúne capacitação porque "em termos de recursos humanos, de instalações e equipamentos tem muito a oferecer. Não só no sentido de difundir e disponibilizar sua produção intelectual, mas também de adequar parte substancial dela às carências da sociedade em que se insere e a que deve servir". Por sua vez, Santos (2004) considera que a universidade deve se transformar e prover reforma nas suas concepções e condutas, no sentido de ser uma instituição canalizadora de mecanismos para a construção de uma sociedade que apoia as necessárias transformações sociais.

Freire (1985) provoca o debate sobre a extensão como "comunicação". O pesquisador sinaliza os compromissos sociais das universidades como 'verbo' daqueles e daquelas que cingem e fundam uma dada contextura social. Recupera-se, assim, a noção de práxis, na qual se situa uma relação sinérgica entre teoria e prática e nessa via, as avaliações do esforço e impacto da inovação social nas Instituições de Ensino Superior (IES) são cruciais (Elliott, 2013).

Silva (2017, p. 65)esclarece que a extensão universitária tem "natureza interdisciplinar, se realiza, em parte, além das salas de aulas e laboratórios, é voltada para o atendimento de demandas por conhecimento e informação de um público amplo, difuso e heterogêneo".
Na América Latina, a extensão universitária foi praticada a partir de parâmetros e motivações das questões sociais na região, durante o século XX e influenciada pela Reforma Universitária, iniciada pelos estudantes de Córdoba, em 1918. Essa Reforma originou-se da luta contra o distanciamento das Universidades dos grandes problemas sociais, econômicos, políticos e culturais das nações latino americanas [...]. Nesse direcionamento, a extensão universitária convoca a Universidade para o aprofundamento de seu papel de transformação social, como colaboradora do processo de empoderamento dos indivíduos (Silva, 2017, p. 66).

A partir da década de 80 , inaugura-se uma fase de democratização da universidade e de fortalecimento da categoria docente - isso amplia e fomenta o debate do termo extensão (Gomez, Corte, \& Rosso, 2019). As pesquisadoras mencionam também que a criação do Fórum dos Pró-Reitores de Extensão das Universidades Públicas Brasileiras (Forproex) foi essencial para a reformulação do tripé universitário (ensino, pesquisa, extensão). Gomez et al. (2019) citam que o Forproex publicou, em 1999, o Plano Nacional de Extensão Universitária (PNEU) - definindo conceitos e diretrizes para a extensão nas universidades brasileiras — e na sequência de treze anos até 2012 esse Plano se transforma em Política Nacional de Extensão.

Prontamente se entende que é dever da Instituição estabelecer uma via de mão dupla entre ela e a sociedade, pois a universidade deve "buscar exercer, com mais amplitude, suas relações com a sociedade, recusando-se a adotar uma postura neutra ou superior diante da realidade social. Deve discutir os problemas prioritários da sociedade [...]" (Jambeiro, 1999, p. 50).

Grosso modo, entende-se que "afinal, os problemas não se reduzem ao campo científico, mas carregam valores e aspectos sociais, éticos e culturais, o que exige uma educação em ciência e tecnologia, uma verdadeira alfabetização científica" (Rosa \& Trevisan, 2016, p.735). Dessa forma, a Universidade, por meio da extensão universitária, tem papel de transferência de conhecimento e mobilização comunitária, de modo que o conhecimento teórico nela adquirido, somado à possibilidade da vivência prática, seja capaz de gerar transformações, em resposta às lacunas de mercado.

A área de extensão vai ter no futuro próximo um significado muito especial. No momento em que o capitalismo global pretende funcionalizar a Universidade e, de fato, transformá-la numa vasta agência de extensão ao seu serviço, a reforma da Universidade deve conferir uma nova centralidade às atividades de extensão (com implicações no currículo e nas carreiras dos docentes) e concebê-las de modo alternativo ao capitalismo global, atribuindo às Universidades uma participação ativa na construção da coesão social, no aprofundamento da democracia, na luta contra a exclusão social e a degradação ambiental, na defesa da diversidade cultural (Santos, 2004, p. 53-54).

Gadotti (2017) aponta que extensão universitária deve ocorrer por meio da interação com a sociedade, promovendo a comunicação entre os saberes científico e popular, de forma a possibilitar a materialização das informações já lançadas a partir da intervenção na realidade. Logo, extensão não está à parte do ensino e da pesquisa, mas entusiasma ambas, intercruzando a ciência, a tecnologia e a prática (Gadotti, 2017). Em síntese, nota-se que:

Hoje, a universidade está atolada em uma luta de concepções, e a perspectiva da extensão vinculada à "transferência de serviços" e à "recuperação de custos" tem um peso enorme que não devemos ignorar. As empresas transnacionais de mineração, agronegócio, petroquímica e petróleo estão em nossos territórios e as universidades são aliadas estratégicas de suas iniciativas, baseadas na teoria da responsabilidade social corporativa. Essa concepção coexiste com a perspectiva assistencialista sem conflito. O segundo aspecto, para Moacir Gadotti, entende a extensão universitária como 
comunicação de conhecimento. É uma versão não assistencial da extensão. A proposta de Paulo Freire de substituir o conceito de extensão pela comunicação vai nessa linha. Baseia-se em uma teoria do conhecimento, respondendo à pergunta: como aprender, como o conhecimento é produzido, uma teoria do conhecimento baseada em uma antropologia que considera todo ser humano como um ser inacabado, incompleto e inacabado, que não sabe tudo, mas isso também não ignora tudo. Pretendemos, e é o esforço, trabalhar a partir dessa perspectiva e desse ponto de vista as fronteiras entre ensino, pesquisa e extensão se confundem. Eles se alimentam, nutrem, dialogam (Visotsky, 2020, p. 1).

Há que se expor, portanto, o fato de a inovação social nas universidades gerar a difusão do conhecimento, utilizando mecanismos que beneficiem e repliquem a expansão dos resultados, espalhando o conhecimento adquirido por meio de experiências bem-sucedidas para outras comunidades (Bignetti, 2011). Nessa perspectiva, a gestão das inovações sociais situa a "busca de ações" como lugares "que minimizem e que, até, eliminem as diferenças sociais" como "parece ser o grande desafio do futuro da Humanidade" (Bignetti, 2011, p. 12).

No âmbito da Ciência da Informação (CI), Felipe e Gomes (2014) afirmam haver uma parceria entre a CI e a Responsabilidade Social Universitária para fins de inclusão social, ou seja:

No atual contexto da sociedade um dos objetivos da CI seria contribuir para a informação se tornar um elemento de inclusão social, trazendo desenvolvimento para os indivíduos e seus grupos sociais. Se considerarmos o conhecimento como resultado da interação do sujeito com o meio social, tecnológico, político e cultural, seremos de acordo que tal situação se apresenta como desafio metodológico para a Ciência da Informação tanto pelo deslocamento do individualismo metodológico, quanto para o seu oposto, o coletivismo metodológico [...] As atitudes de responsabilidade ética e social que começam a ser praticadas no meio universitário, ainda necessitam de muito fermento para se reproduzirem de forma amplificada [...] Retornando, repetindo e reforçando! Imaginamos a RSU [Responsabilidade Social Universitária] com atitudes de respeito, praticadas com comportamentos éticos, moralmente corretos; com respeito aos padrões universais de direitos humanos e de cidadania e com a participação de toda a sociedade; com respeito às diversidades e aos diferentes, sem discriminações (Felipe \& Gomes, 2014, p. 153-161).

Nesse painel, a responsabilidade social é um fenômeno capaz de melhorar o agir em sociedade (Dias Sobrinho, 2015). Dentro desse enfoque, Tosta, Spanhol, e Tosta (2016) esclarecem que qualquer um que tenha interesse pode se tornar parte da inovação, vendo na responsabilidade social um modo de criar novas e efetivas respostas aos desafios do mundo atual. Nesse perímetro criativo, não existem limites para a responsabilidade social. Há diferentes formas de se fazer desenvolver a RSU por setores públicos (sem fins lucrativos), na esfera privada, ou, ainda, na junção dos âmbitos e parcerias.

Oliveira, Tosta, e Freitas (2020, p. 124) apontam que curricularização (forma como as atividades e ou disciplinas de extensão poderão ser inseridas às matrizes curriculares dos cursos) da extensão carece de ser explorada de forma mais "veemente e exaustiva, na possibilidade de trazer informações que possam contribuir com a inserção da extensão na matriz curricular dos cursos de graduação e orientar as futuras pesquisas a respeito da temática". Os pesquisadores alertam que a extensão é a base do compromisso da universidade "com a população, além de exercer a função de estabelecer parâmetros na formação de ensino - aprendizagem acadêmica. Certifica-se que a creditação traz consigo uma série de reflexões conceituais sobre extensão, bem como o fato de ser um desafio para as IES" (Oliveira et al., 2020, p. 124).

Silva e Deboçã (2018, p, 125) pautam a questão do Impacto e Transformação Social na extensão universitária. Nesse caso, os autores compreendem que a extensão reafirma o alvitre de "inter-relação da universidade com os demais setores da sociedade com vistas à atuação transformadora, voltada para interesses e demandas da maioria da população e causadora não só de desenvolvimento social e regional como também de aprimoramento de políticas públicas".

\section{MATERIAL E DECURSO METODOLÓGICO}

Inicialmente, buscou-se um conjunto de dados e atividades da RSU na universidade analisada e, após análise documental, procedeu-se à categorização dos itens, tendo em mente a seleção das ações (Quadro 1) e dos projetos (Quadro 2) direcionados à pandemia. Nesse enquadramento foram identificados um banco de dados composto de cinco programas de ação e dez projetos - uma pauta em critérios de exequibilidade a totalizar 15 direcionamentos, como a seguir. 


\begin{tabular}{|l|c|c|c|c|}
\hline \multicolumn{5}{|c|}{ A Ufes na rede colaborativa para o enfrentamento ao novo coronavírus no ES } \\
\hline Açães de Extensão & Unidade & Classificação & Registro & Unidade \\
\hline $\begin{array}{l}\text { Curso de Extensão: forma- } \\
\text { ção em Gramsci em tempos de } \\
\text { pandemia }\end{array}$ & $\begin{array}{c}\text { Departamento de Serviço } \\
\text { Social - DSS/CCJE }\end{array}$ & $\begin{array}{c}\text { Curso ou Oficina de } \\
\text { Extensão }\end{array}$ & $01 / 06 / 2020$ & 1701 \\
\hline $\begin{array}{l}\text { Curso de Extensão em Direi- } \\
\text { tos Humanos para professo- } \\
\text { res/as do sistema prisional ca- } \\
\text { pixaba em tempos de pande- } \\
\text { mia }\end{array}$ & $\begin{array}{c}\text { Departamento de Serviço } \\
\text { Social - DSS/CCJE }\end{array}$ & $\begin{array}{c}\text { Curso ou Oficina de } \\
\text { Extensão }\end{array}$ & $03 / 06 / 2020$ & 1768 \\
\hline $\begin{array}{l}\text { A educação no contexto da } \\
\text { pandemia do Estado do Espí- } \\
\text { rito Santo: as escolas estão } \\
\text { preparadas para o retorno pre- } \\
\text { sencial? }\end{array}$ & $\begin{array}{c}\text { Departamento de } \\
\text { Educação, Política e } \\
\text { Sociedade - DEPS/CE }\end{array}$ & Evento de Extensão & $22 / 06 / 2020$ & 1767 \\
\hline $\begin{array}{l}\text { Extensão no Herbário VIES } \\
\text { durante a pandemia da covid- } \\
19\end{array}$ & $\begin{array}{c}\text { Departamento de Ciências } \\
\text { Biológicas - DCB/CCHN }\end{array}$ & Evento de Extensão & $01 / 06 / 2020$ & 1782 \\
\hline
\end{tabular}

Quadro 1. Ações de extensão universitária ao enfrentamento da pandemia do coronavírus

Fonte: Elaborado pelos autores com base em Universidade Federal do Espírito Santo. Pró-reitoria de Extensão (2020b) e Rede Nacional de Extensão (2020).

A gama de projetos e programas extensionistas mostra-se bastante diversificada e em diferentes dimensões do combate à pandemia. Mostra-se ainda alinhada com as especialidades e potenciais de cada departamento, como no caso do monitoramento de idosos, desenvolvido no âmbito do departamento de enfermagem. Ou como nos casos dos departamentos de matemática e de computação, com projetos alinhados à produção de vídeos e de suporte à informática. O Quadro 2 apresenta um panorama dessa observação.

\begin{tabular}{|c|c|c|c|}
\hline \multicolumn{4}{|c|}{ Publicações de Projetos de Extensão } \\
\hline Projetos de Extensão & Unidade & Início & Registro \\
\hline $\begin{array}{l}\text { Psicologia, cuidado e enfrentamento a } \\
\text { pandemia da covid-19: integração de } \\
\text { ações de suporte frente à situação de } \\
\text { emergência ocasionada pelo coronaví- } \\
\text { rus }\end{array}$ & $\begin{array}{l}\text { Departamento de } \\
\text { Psicologia Social e } \\
\text { Desenvolvimento - } \\
\text { DPSD/CCHN }\end{array}$ & $01 / 04 / 2020$ & 1594 \\
\hline $\begin{array}{l}\text { Ação de monitoramento de idosos du- } \\
\text { rante a pandemia de coronavírus }\end{array}$ & $\begin{array}{l}\text { Departamento de } \\
\text { Enfermagem - DE/CCS }\end{array}$ & $07 / 04 / 2020$ & 1618 \\
\hline $\begin{array}{l}\text { Desenvolvimento de estudos e proje- } \\
\text { ções matemáticas da pandemia de covid- } \\
19 \text { no Espírito Santo }\end{array}$ & $\begin{array}{c}\text { Departamento de } \\
\text { Matemática- DM/CCE }\end{array}$ & $09 / 03 / 2020$ & 1630 \\
\hline $\begin{array}{l}\text { A matemática no desenvolvimento e pro- } \\
\text { dução de máscaras tipo escudo facial } \\
\text { para profissionais de saúde na pandemia } \\
\text { de covid-19 }\end{array}$ & $\begin{array}{c}\text { Departamento de } \\
\text { Matemática- DM/CCE }\end{array}$ & $17 / 03 / 2020$ & 1631 \\
\hline $\begin{array}{l}\text { A matemática no desenvolvimento e pro- } \\
\text { dução de vídeos educativos de conscien- } \\
\text { tização da população em geral com rela- } \\
\text { ção à pandemia de covid-19 }\end{array}$ & $\begin{array}{l}\text { Departamento de } \\
\text { Matemática-DM/CCE }\end{array}$ & 020 & 1632 \\
\hline $\begin{array}{l}\text { Divulgação científica em tempos de pan- } \\
\text { demia }\end{array}$ & $\begin{array}{l}\text { Departamento de Ciências } \\
\text { Biológicas - DCB/CCHN }\end{array}$ & $01 / 04 / 2020$ & 1663 \\
\hline $\begin{array}{l}\text { Suporte social em informática durante a } \\
\text { pandemia de covid-19 }\end{array}$ & $\begin{array}{c}\text { Departamento de } \\
\text { Computação- DC/CCENS }\end{array}$ & $13 / 05 / 2020$ & 1677 \\
\hline $\begin{array}{l}\text { Clube de leitura de obras literárias que } \\
\text { tematizam pestes, epidemias ou pande- } \\
\text { mias }\end{array}$ & $\begin{array}{l}\text { Departamento de } \\
\text { Linguagens, Cultura e } \\
\text { Educação- DLCE/CE }\end{array}$ & $11 / 06 / 2020$ & 1697 \\
\hline $\begin{array}{l}\text { Orientações nutricionais para pacien- } \\
\text { tes com câncer durante a pandemia de } \\
\text { covid-19 }\end{array}$ & $\begin{array}{l}\text { Colegiado do Curso de } \\
\text { Nutrição - CCN/CCS }\end{array}$ & $01 / 06 / 2020$ & 1716 \\
\hline
\end{tabular}




\begin{tabular}{|l|c|c|c|}
\hline \multicolumn{3}{|c|}{ Publicações de Projetos de Extensão } \\
\hline Projetos de Extensão & Unidade & Início & Registro \\
\hline $\begin{array}{l}\text { Roda de conversa: educação em tempos } \\
\text { de pandemia }\end{array}$ & $\begin{array}{c}\text { Departamento de } \\
\text { Psicologia - DP/CCHN }\end{array}$ & $22 / 04 / 2020$ & 1805 \\
\hline
\end{tabular}

Quadro 2. Projetos e programas extensionistas de prevenção e enfrentamento à Covid-19

Fonte: Elaborado pelos autores com base em Universidade Federal do Espírito Santo. Pró-reitoria de Extensão (2020b) e Rede Nacional de Extensão (2020).

Considerando os objetivos propostos para este estudo, utilizou-se análise descritiva e se optou como técnica de pesquisa a análise de conteúdo proposta por Bardin (1985, p. 40), para quem a "análise de conteúdo aparece como um conjunto de técnicas de análise das comunicações que utiliza procedimentos sistemáticos e objetivos de descrição do conteúdo das mensagens".

A Rede Nacional de Extensão (2020) que, nesse momento de crise mundial, a Ufes está promovendo diversas ações extensionistas para mitigar os efeitos da pandemia da Covid-19. A Instituição vem propondo e realizando ações que contribuem para o enfrentamento dos efeitos da pandemia, ajuizando alternativas para a continuidade da vida em sociedade.

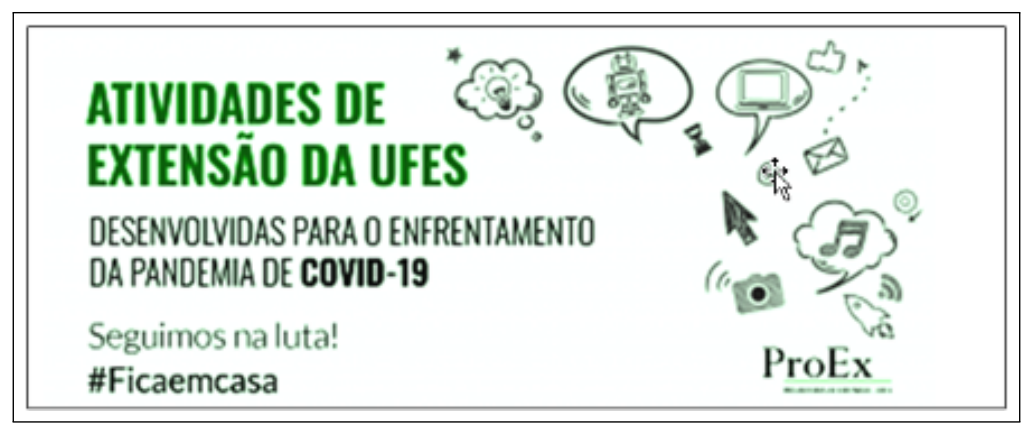

Figura 1. Rede colaborativa da Ufes frente à Covid-19.

Fonte: Universidade Federal do Espírito Santo. Pró-reitoria de Extensão (2020a).

A Ufes passou, por conseguinte, a integrar a Rede Colaborativa para enfrentamento à pandemia da Covid-19 no Espírito Santo (RCEP, portaria SESA no 061-r abr. 2020) que tem promovido ações nas áreas de saúde (nutrição, psicologia, farmácia, medicina, enfermagem, terapia ocupacional), assistência social, incluindo o campo da educação financeira, tecnológica, científica, cultural e artística. Além disso, frisa-se que os servidores e alunos têm se mobilizado para contribuir com informações importantes e necessárias, produzindo textos e lives nas redes sociais. Um exemplo dessa prática são as lives 'Depois do coronavírus' e o canal do 'PET-Psicologia', que estão divulgando vídeos com orientações e considerações sobre a pandemia.

Registro das Ações: novas ações estão surgindo a cada dia, mostrando que a comunidade acadêmica da Ufes está ciente do seu papel nessa crise mundial sem precedentes. A Proex salienta a importância dessas ações serem devidamente registradas no Sistema de Registro da Extensão, para que possam ser contabilizadas e terem a devida visibilidade, bem como para permitir a devida certificação de seus autores e agentes (Universidade Federal do Espírito Santo. Pró-reitoria de Extensão, 2020a, p. 1).

Outro painel de ação remete à mobilização dos servidores da Ufes. Como exemplo temos a nota emitida por pesquisadores no campo das Políticas Sociais, com proposições de ações sociais e econômicas para o enfrentamento da crise como: a) ações sociais e econômicas para combate ao coronavírus; b) ações de proteção à primeira infância ante a Covid-19; e c) a distribuição do benefício do Auxílio Emergencial no Estado do ES.

Como pesquisadores do campo da Política Social, vinculados ao Programa de Pós-Graduação em Política Social e aos Departamentos de Serviço Social, Economia, Ciências Sociais e Música da Ufes, produzimos este documento para contribuir com o combate ao coronavírus [...]. O Estado brasileiro possui todos os instrumentos necessários para viabilizar todas as medidas de salvaguarda da população. Tanto o monopólio da força [Justiça] quanto a emissão da moeda-dinheiro [Banco Central] são prerrogativas exclusivas do Estado. Tais ferramentas lhe conferem condições mais do que suficientes para lidar com os impactos sociais e econômicos no curto, médio e longo prazo. Assim, assevera-se nesse documento que a preocupação primeira deve ser sempre com a vida da população. [...] Talvez, para além do temor à morte, o surgimento da covid-19 tenha despertado uma das maiores fragilidades do ser humano: a solidão [...]. No decorrer desse processo, os estímulos sociais se mostram como os verdadeiros elos da civilização. A solidariedade (ao invés egoísmo), a cooperação (ao invés da competição), a partilha (ao invés da acumulação), a compaixão (ao invés da indiferença) e, principalmente, a amizade (ao invés do oportunismo) solidificam-se como os verdadeiros bastiões da sociedade (Universidade Federal do Espírito Santo. Portal Coronavirus, 2020, p. 1-8). 
Cada qual, consequentemente, no seu campo de atuação, alvitrando e realizando ações que colaboram para o enfrentamento das implicações da pandemia, ponderando em vicissitudes para o prosseguimento da vida em sociedade.

\section{APRESENTAÇÃO E DESCRIÇÃO DE AÇÕES DA UFES NO ENFRENTAMENTO À COVID-19}

Os quadros anteriores mostram um cenário de ações e projetos de enfrentamento à pandemia, que refletem o papel da atividade extensionista no desenvolvimento da Responsabilidade Social Universitária. Nas ações e nos projetos mostrados, aparecem a missão universitária de geração e transferência de conhecimento e de inovações com vistas à formação de pessoas, além de iniciativas para o desenvolvimento social e sustentável. No entanto, muitas outras ações foram desenvolvidas no âmbito da universidade pesquisada.

Listamos aqui mais alguns exemplos das ações desenvolvidas:

- Comunicação: orientação de exercícios na quarentena; a Superintendência de Comunicação (Supec) cria canal de comunicação sobre o coronavírus; divulgação de ações e informações nas redes sociais da Proex Ufes — expõem ações e informações nas redes dos projetos de extensão, principalmente no endereço eletrônico do Museu de Ciência da Vida (MCV) e na web (página da internet) divulgação de ações da Ciência da Proex <http://divulgacaodaciencia.ufes.br >; a preparação de canal de monitoramento à Covid-19 no ES por professores de Biologia do Centro de Ciências Exatas, Naturais e da Saúde (CCENS); professores do Departamento de Matemática (DMAT) preparam modelo matemático para monitoramento da pandemia; professores de Ciência da Computação do CCENS (campus da Ufes no município de Alegre) criam site para acompanhamento de casos da Covid-19.

- Saúde e bem-estar: nutrição em tempo de quarentena e Cartilha de Serviços Delivery - o que é preciso saber ao receber alimentos, elaborada pela equipe do projeto de extensão "Boas práticas de manipulação em serviços de alimentação", ensinando o que é preciso saber, em tempos de Covid-19 ao receber comidas. Esse Projeto de Extensão avalia e orienta para a produção de alimentos seguros, além de aconselhar sobre cuidados e higiene dos alimentos, especialmente em tempos de pandemia; kit teste rápido: desenvolvimento de técnicas para a produção de kits rápidos de teste; Psicologia: criação do canal on-line sobre saúde mental, mostrando o cuidado e enfrentamento da pandemia de covid-19 e a integração de ações de suporte frente a situação de emergência ocasionada pelo coronavírus.

- Hospital Universitário Cassiano Antonio Moraes (Hucam): suporte científico sobre Covid-19 para auxiliar na prática clínica dos Fisioterapeutas do Hucam e outros serviços; a Teleconsultoria Especializada, serviço do Hucam, para atender demandas e dúvidas de profissionais de Atenção Primária de todo o Estado do Espírito Santo.

- Assistência Social: auxílio emergencial para estudantes atendidos pelos programas de assistência estudantil; ações de entidades como a Central Única das Favelas do Espírito Santo (CUFA-ES), que tem feito um trabalho importante junto às famílias de trabalhadores autônomos que estão sem trabalho e renda nesse período.

- Utilidade pública: a fabricação de protetores faciais para profissionais da Saúde; a Criação do Laboratório de manutenção de equipamentos hospitalares (Centro Tecnológico) para atender as demandas da rede estadual de Saúde; Voluntariado: a Ufes conta com seis frentes de trabalho, na área tecnológica, que estão urgentemente necessitando do conhecimento técnico e da força de trabalho de todos os servidores e alunos de pós-graduação da área; a manufatura de Equipamentos de Proteção Individual (EPIs) e peças para equipamentos; produção de escudos de proteção facial utilizando as impressoras 3D disponíveis e máquinas de corte a laser; produção de Álcool em Gel: produzir álcool em gel para distribuição em hospitais do estado; Ciências Contábeis e o canal de atendimento a pequenos e médios empresários; campanha de doações: doação de cinco toneladas de alimentos dos restaurantes universitários e o reforço da Associação dos Docentes da Ufes (Adufes) nas campanhas de arrecadação; manutenção de equipamentos hospitalares: montagem de laboratórios para a manutenção de ventiladores mecânicos, respiradores e equipamentos de pequeno porte que deverão ser usados em pacientes acamados em virtude da Covid-19. Utilização de espaços do CT-6 térreo e/ou do anexo do CT-3. Em paralelo, a necessidade de uma equipe de manutenção de macas e leitos hospitalares; Tecnologia: Ufes cede equipamentos para a Secretaria de Estado da Saúde; Produção de antissépticos a base de álcool $70 \%$ no Departamento de Ciências Farmacêuticas no Centro de Ciências da Saúde da Ufes, utilizando as estruturas laboratoriais do Departamento de Farmácia, Laboratórios de Anatomia e Plastinação do Departamento de Morfologia, localizados no Centro de Ciências da Saúde (CCS) - Campus de Maruípe, em Vitória.

- Tecnologias da informação e comunicação (TICs): a infraestrutura de TIC desenvolve várias iniciativas utilizando computação em nuvem, Internet of Things (IoT) e outras tecnologias em parceria com empresas locais; logística, processos e modelagem: a logística, processos e modelagem tem como objetivo ajudar o governo do ES com a modelagem de processos em tempos de crise e seus aspectos logísticos. 


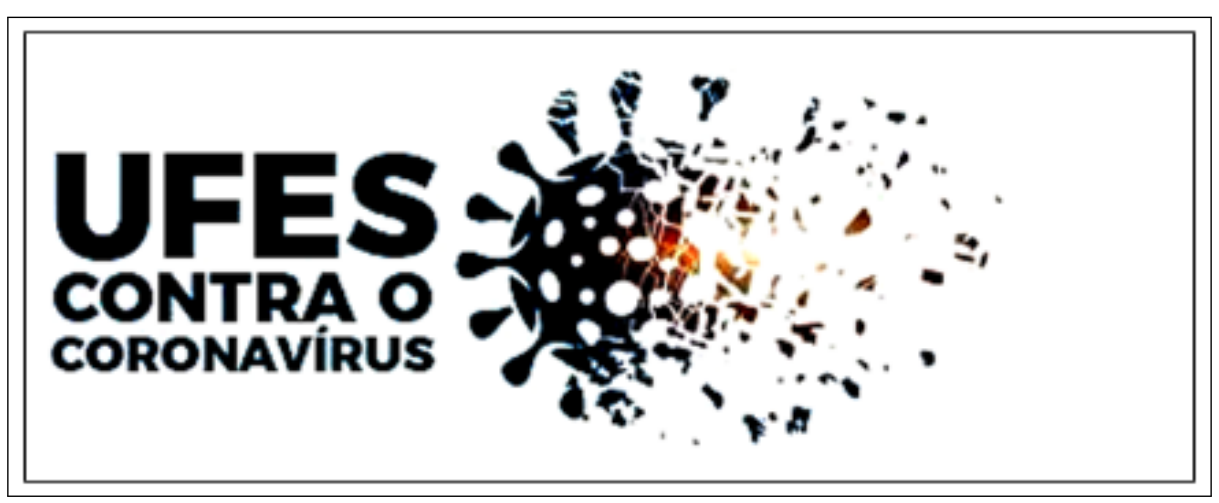

Figura 2. Ufes e as propostas de projetos e ações que visem ao combate à Covid-19. Fonte: Universidade Federal do Espírito Santo. Pró-reitoria de Extensão (2020a).

Muitas são as recomendações, medidas e ações universitárias relativas ao enfrentamento da Covid-19. Por isso, resgatando o trabalho de Sales, Silva, e Maciel (2020, p.4) reafirma-se que a educação em saúde, concretizada com linguagem, informações e orientações francas à comunidade interna e externa, tornam-se altamente necessárias para, assim, "evitar o efeito negativo de mensagens falsas (fake news) que circulam na internet, além de atingir um maior número de pessoas que, uma vez orientadas, podem tornar-se multiplicadoras da informação de qualidade". Nesse painel, vemos a importância do projeto 'Saúde Sem Fake News' em torno do qual o governo projeta um Canal no WhatsApp que reporta informações sobre notícias verdadeiras ou falsas.

A Proex, com a finalidade de fortalecer o engajamento e a solidariedade da comunidade universitária e da sociedade externa na adoção de soluções para a área de educação, lançou o Projeto 'Solidariedade Digital' para promover a inclusão digital dos estudantes que fazem parte do programa de assistência estudantil (sete mil alunos, 2020/1) da Ufes. Este fato se torna ainda mais relevante nas condições "sanitárias atuais, em que a pandemia de Covid-19 suprimiu as possibilidades de acesso que são oferecidas pela Universidade em situação presencial por meio da disponibilização de equipamentos e softwares de uso coletivo nos diversos laboratórios dos seus campi" (Universidade Federal do Espírito Santo. Pró-reitoria de Extensão, 2020b, p. 1).

Por meio da análise dos dados coletados e categorizados há um rol de programas - projetos de extensão - que apresentam sedimentares indícios de inovação social, considerando-se, especialmente: a) as motivações que suplantaram o início de cada um deles; b) suas finalidades, pautadas no atendimento pontual de lacunas, do mercado e do governo, no atendimento de demandas sociais; e c) seus resultados, considerando-se as novas redes de relacionamentos constituídas, que nasceram com o programa ou os projetos de extensão analisados nesse estudo. A seguir, o Quadro 3 mostra dois exemplos de determinantes no nível macro.

\begin{tabular}{|c|c|c|}
\hline \multicolumn{3}{|c|}{ "Vida acima dos lucros, enfrentar a pandemia é possível e necessário jả" } \\
\hline \multirow{2}{*}{ Fatores determinantes e condicionantes } & Características Gerais & Resultados \\
\hline & $\begin{array}{l}\text { As motivações, atuação e } \\
\text { finalidades }\end{array}$ & Redes de relacionamentos \\
\hline Vida acima do lucro & $\begin{array}{l}\text { Fazer divulgação científica, } \\
\text { relacionando o mundo do } \\
\text { trabalho e a pandemia de } \\
\text { coronavírus. Para tanto se fazem } \\
\text { lives na página do Instagram e } \\
\text { práxis com entrevistas com } \\
\text { especialistas, entidades sociais e } \\
\text { sindicais. }\end{array}$ & $\begin{array}{l}\text { Envolve estudantes de graduação } \\
\text { e pós-graduação com } \\
\text { aprofundamento na temática } \\
\text { além de engajamento na } \\
\text { divulgação científica. }\end{array}$ \\
\hline $\begin{array}{l}\text { Saúde em Movimento } \\
\text { frente ao coronavírus }\end{array}$ & $\begin{array}{l}\text { O cenário atual de pandemia pela } \\
\text { covid-19 tem contribuído para } \\
\text { que inúmeros trabalhadores da } \\
\text { saúde sejam solicitados de forma } \\
\text { mais intensiva nos atendimentos } \\
\text { hospitalares e tenham suas } \\
\text { rotinas de trabalho alteradas, } \\
\text { tendo que se adaptarem ao novo } \\
\text { panorama. }\end{array}$ & $\begin{array}{l}\text { Desenvolve atividade física e } \\
\text { hábitos de vida saudáveis no } \\
\text { ambiente de trabalho dos } \\
\text { funcionários do HUCAM por } \\
\text { meio de motivação, apoio e } \\
\text { orientações especializadas para } \\
\text { ajudar no enfrentamento de } \\
\text { emergência. }\end{array}$ \\
\hline
\end{tabular}

Quadro 3. A vida acima do lucro: divulgação científica em tempos de coronavírus.

Fonte: Elaborado pelos autores com base em Universidade Federal do Espírito Santo. Pró-reitoria de Extensão (2020b) e Rede Nacional de Extensão (2020). 
Pelo que foi constatado na primeira fase de categorização, o programa e os projetos de extensão descritos têm perfil inovador e cunho assistencial, suportando as características de responsabilidade social, além de estarem alinhados com o compromisso social da universidade.

Apresentam-se, a seguir, as características de responsabilidade social identificadas nos projetos e programas analisados, obtidos por meio de entrevistas presenciais, gravadas em áudio e posteriormente categorizadas no quadrante características de inovação social. A seguir, o Quadro 4 mostra alguns exemplos de determinantes no nível micro; além disso, situa vínculos de compromisso e de corresponsabilidade com a população, agindo de forma multidisciplinar com intervenções que têm efeitos determinantes sobre as condições de vida e saúde dos indivíduos.

\begin{tabular}{|c|c|c|}
\hline \multicolumn{3}{|c|}{ Responsabilidade social da Ufes nos projetos e programas de extensão universitária } \\
\hline & Relações sociais & Direcionamento de ações \\
\hline Eventos & $\begin{array}{c}\text { Novas Práticas com foco no } \\
\text { bem-estar social }\end{array}$ & Expansão \\
\hline $\begin{array}{l}\text { Evento de Extensão - } \\
\text { Depois do coronavírus }\end{array}$ & $\begin{array}{c}\text { Tanta informação e } \\
\text { desinformação é mais um fator } \\
\text { agravante desta experiência } \\
\text { inédita para muitos de nós. Ela } \\
\text { nos transformará? Deixará } \\
\text { marcas na nossa cultura, moral, } \\
\text { espiritualidade e econômica? Em } \\
\text { meio ao turbilhão do vírus, este } \\
\text { projeto apresenta uma série de } \\
\text { conversas com especialistas } \\
\text { diversos sobre temas como } \\
\text { saúde, justiça, política, cultura, } \\
\text { comunicação. }\end{array}$ & $\begin{array}{l}\text { Para compartilhar algumas } \\
\text { aflições e ideias esperançosas em } \\
\text { um momento difícil para todos } \\
\text { nós. As entrevistas são } \\
\text { divulgadas no canal }{ }^{a} \text { Julio } \\
\text { Pompeu do YouTube. }\end{array}$ \\
\hline $\begin{array}{l}\text { Curso Decifrando o co- } \\
\text { ronavírus: Covid-19 e a } \\
\text { Biologia Celular }\end{array}$ & $\begin{array}{c}\text { Oferecer alternativas de } \\
\text { divulgação científica e } \\
\text { conscientização à comunidade } \\
\text { externa e acadêmica no contexto } \\
\text { da pandemia atual, dando ênfase } \\
\text { em conhecimentos da Biologia } \\
\text { Celular. Utilizar a plataforma } \\
\text { Coursify.me, por meio de vídeos } \\
\text { aulas e acompanhamento para } \\
\text { dúvidas e sugestões. }\end{array}$ & $\begin{array}{l}\text { Divulgação em rede social da } \\
\text { cidade de São Mateus à } \\
\text { comunidade local; alcançar as } \\
\text { famílias ligadas ao ensino do } \\
\text { CEUNES. }\end{array}$ \\
\hline
\end{tabular}

Quadro 4. Características de responsabilidade social nos projetos e programas analisados.

Fonte: Elaborado pelos autores com base em Universidade Federal do Espírito Santo. Pró-reitoria de Extensão (2020b) e Rede Nacional de Extensão (2020).

\footnotetext{
${ }^{a}$ Canal de conteúdo sobre os dilemas da quarentena para o YouTube < www.youtube.com/c/JulioPompeu $>$. Em suma, apurar-se que um volume imenso de informações contraditórias nos bombardeia quotidianamente. Os vídeos buscam a discutir as informações de lockdown, guideline e home office inerentes as atitudes dos internautas de maneira simples e atrativa. Idealizado pelo por Doutor em Psicologia Julio Pompeu - o canal produz uma série de 'provocações' sobre o pensar e o sentir. O canal está em atividade desde 2007, com mais de 40 vídeos produzidos (playlists).
}

Pode-se verificar, no Quadro proposto, que o programa e os projetos de extensão aqui analisados não dão continuidade, de modo geral, a modelos preexistentes de atuação na sua concepção, ou seja, foram readaptados. Ainda a respeito dos resultados apresentados na sistematização do Quadro 3, faz-se relevante salientar que nessa fase da análise dos dados, o programa e os projetos de extensão estudados geraram modelos de operação capazes de serem replicados em outras comunidades e esferas. Nesse sentido, parece factível afirmar que os programas e projetos de extensão estudados possuem a característica de responsabilidade social defendida por Visotsky (2020), alinhando-se estrategicamente a diversas empresas, nacionais e transnacionais, com objetivos assistenciais comuns, visando ao bem da comunidade externa.

Finalizando a descrição e análise dos dados, apresentam-se, no Quadro 04, os principais apontamentos categorizados, referentes a impactos sociais gerados com a atuação do programa e dos projetos de extensão analisados. Nessa fase, recorre-se a Elliott (2013), ao apontar que, do ensino superior, espera-se a contribuição de diplomados qualificados para o crescimento econômico, para a melhoria da qualidade de vida e para inclusão social na construção de comunidades.

Uma observação das ações e projetos com características de clara responsabilidade social carregam em si a intenção de gerar e carregam esse potencial e por meio de programas ou nos projetos de extensão, enriquecimento 
pessoal; sentimentos de responsabilidade; acesso a outras realidades sociais; busca de maior conhecimento na temática foco do projeto e; uma visão diferenciada do mundo, para além dos muros da universidade.

Em suma, os programas, as propostas e chamadas de projetos ou as ações de pesquisa, inovação e extensão analisados influenciam na comunicação de saberes sobre a doença, geram o engajamento social e inovações, criam empoderamento pessoal e formas de solidariedade, auxiliam na formação de leis e das novas redes entre grupos sociais (rede colaborativa para o enfrentamento do novo coronavírus), entre outros aspectos positivos.

Nas palavras de Silva e Deboçã (2018), "o impacto social pode ser compreendido como mudanças no estado de pessoas afetadas por problema social específico, oriundas de uma ação, atividade, processo, projeto ou políticas operadas por indivíduos ou instituições." Esse foi o caminho percorrido até aqui, pois a universidade, imersa como está em uma luta de concepções e interesses, sua perspectiva da extensão ligada à "transferência de serviços e produtos" tem um peso de enorme importância que não se deve ignorar, uma vez que coexiste com a perspectiva assistencialista, sem conflito.

A extensão, portanto, envolve uma vasta área de prestação de serviços e os seus destinatários são múltiplos: grupos sociais populares e suas organizações; movimentos sociais; comunidades locais ou regionais; governos locais; setor público; setor privado. Para além de serviços prestados a destinatários bem definidos, há também a influência digital e a criação de conteúdo, como por exemplo: i) as cartilhas — com orientações públicas, durante o período de quarentena, motivadas pela pandemia de Covid-19, a doença decorrente do Sars-CoV-2; ii) iniciativas para contribuir no combate ao novo coronavírus em publicações oficiais; iii) gestão de dados com um rol de informações de diversas iniciativas da Ufes (ou que contam com o apoio e a participação da universidade); apresentação de dados relativos à doença causada pelo novo coronavírus (Covid-19) ou às ações da Ufes para contribuir no combate à pandemia.

Em face disso, buscou-se compreender como o paradigma social da Ciência da Informação contribui no desenvolvimento de ações extensionistas — em que o bibliotecário possa atuar em segmentos diversos, no sentido de facilitar o acesso à informação, principalmente em contextos de exclusão social. Na visão de Tosta et al. (2016), o impacto social pode ser entendido como mudanças substanciais ou permanentes na vida das pessoas.

Outrossim, os programas inseridos na Proex recebem uma dotação orçamentária que pode ser utilizada de acordo com prioridades estabelecidas pelos próprios programas, uma vez que a universidade vem solicitando às instâncias legais o registro adequado dessas atividades.

\section{PALAVRAS REFLEXIVAS FINAIS}

Foram analisados, neste estudo, a ocorrência de responsabilidade social nos projetos de extensão em andamento na Universidade Federal do Espírito Santo, além da relação de ações extensionistas provocadas pela pandemia da Covid-19 que estão sendo desenvolvidas pela mesma Instituição de ensino. O escopo do trabalho ancora-se na ideia de que as universidades, lugares de excelência onde circulam profissionais de diversas áreas, têm papel importante a desempenhar, em termos de saúde e em prol da coletividade.

Grosso modo, ninguém está preparado para enfrentar medo, morte, dor, incertezas, isolamento e demais agruras que afetam a saúde emocional de toda a comunidade. É esse o lugar de pesquisa, entretanto, onde se pode abarcar processos de inovação social, conforme relatam Gattai e Bernardes (2013), no sentido de atuar na sociedade como sujeito de construção de saberes.

O enfoque analítico, destarte, situa a extensão universitária e as interações na comunidade. Uma universidade atuante (viva), deve, logo, agir em prol de enredos de inovação social e comunitária. Ao pesquisar a interligação da produção de conhecimento de uma universidade e a transferência dessa informação para a sociedade, observa-se a atuação da extensão universitária. Busca-se, então responder à seguinte provocação: em quais projetos, atualmente, a extensão da Universidade pública federal (Ufes) tem-se direcionado ao 'combate' à pandemia do novo coronavírus?

Desse modo, nunca é demais ecoar que a escopo da educação é a "humanização, a formação das pessoas humanas, e mais do que qualquer outra prática social, cabe a ela, nessa condição, investir na construção da autonomia das pessoas, respeitando e consolidando sua dignidade" (Soares \& Severino, 2018).

Observa-se no trabalho de Costa e Miguel (2019) que o Projeto de Reestruturação e Expansão das Universidades (Reuni) viabilizou não só a ampliação de vagas de curso na Instituição, bem como a criação de novos cursos e a ampliação no quadro de servidores. Com isso "também aumentam os números de programas de extensão e ampliam-se as pesquisas, havendo então uma alteração na estrutura" dos quatro campi universitários — o de Goiabeiras e o de Maruípe (ambos de Vitória), o de São Mateus e o de Alegre (Costa \& Miguel, 2019, p. 6).

Em suma, averiguar-se que a universidade carrega um alerta para os enfrentamentos necessários, dinamizando a comunicação extensionista e delimitando as predileções políticas, ideológicas e éticas que podem coadjuvar ou não a propagação de atividades universitárias no âmbito local ou nacional. Ainda Maciel et al. (2020) destacam 
que a "ausência de articulação do governo federal para lidar com os desafios da pandemia, diante o contexto de isolamento social, organização das ações da saúde e da suspensão das aulas, reflete na profunda invisibilidade" enfrentadas pelas Pessoas com Deficiência $(\mathrm{PcD})$.

A emergência da Covid-19, ou melhor, a emergência do combate ao problema, faz defrontar o inimigo invisível que é essa doença. Nesse momento, há precisão por um lado da atuação de um Estado forte; de forma que "diante do risco de morte, a humanidade olhe para si a fim de buscar respostas de como irá superar essa pandemia e todos os efeitos decorrentes dela" (Programa de Pós-Graduação em Política Social da Ufes, 2020, p. 8). Novas formas de atuar pautadas na inovação social, conforme definida por Bignetti (2011), preveem a participação e a cooperação dos atores envolvidos ao aplicar conhecimentos e obter novas e duradouras soluções para grupos sociais, comunidades ou a sociedade como um todo.

Em síntese, o resultado, por meio da análise dos dados coletados e categorizados, apresenta um rol de programas — projetos de extensão — sedimentares indícios da inovação social, considerando especialmente: a) as motivações que suplantaram o início de cada um deles; b) suas finalidades, pautadas no atendimento pontual de lacunas, do mercado e do governo, no atendimento de demandas sociais; e c) seus resultados, considerando-se as novas redes de relacionamentos constituídas, que nasceram com o programa ou com os projetos de extensão analisados neste estudo.

Nesse sentido é possível situar, com o mesmo olhar de Gadotti (2017) e Freire (1985), a extensão universitária como comunicação de conhecimento. Isso se apoia em uma antropologia que considera todo ser humano como incompleto e inacabado, que não sabe tudo, mas que também não ignora tudo. Ademais, por se tratar de uma pesquisa qualitativa, os resultados encontrados e aqui descritos não podem ser utilizados para a generalização, porquanto estes se referem particularmente a quinze ações de extensão de uma única universidade federal localizada em solo capixaba ${ }^{1}$

O vindouro pelos quais Ufes e outras IES tanto lutam, no sentido da efetiva política e da justiça social, chamando a atenção para a importância do comprometimento da universidade e dos poderes públicos com a saúde. Esse compromisso é, ainda hoje, uma questão de sobrevivência social, cultural e política. Assim, a extensão comportase nessa direção como redes sociais e territórios de significados no quadro da cultura informacional, e demanda a interdisciplinaridade para o estudo dos seus objetos pelo ângulo das práticas sociais de informação, inaugurando novas metodologias para ampliar saberes.

Sobre o aponte de limitação da pesquisa, ressalta-se que a interpretação sobre a realidade analisada não adentra em todas as possíveis contribuições que, algumas vezes, não são comunicadas de forma propositada. Nesse painel, esta pesquisa e estudos similares em outras universidades brasileiras, visam identificar as características de responsabilidade social nas iniciativas de extensão universitária, as quais possam sugerir relações substantivas para acompanhar o enfrentamento da pandemia e a formulação e implementação de políticas, diretrizes e projetos estratégicos relativos ao enfrentamento da Covid-19.

\footnotetext{
${ }^{1}$ A Ufes é instituição proponente ou parceira em quase a totalidade das ações de extensão ofertadas no Estado. Mantém parcerias com as secretarias dos governos estadual e municipais, Organizações não Governamentais (ONGs), empresas privadas e outras IES, entre elas o Instituto Federal do Espírito Santo (Ifes).
} 


\section{REFERÊNCIAS}

Bardin, L. (1985). Análise de conteúdo. Lisboa: Edições 70 .

Bignetti, L. P. (2011). As inovações sociais: uma incursão por ideias, tendências e focos de pesquisa. Ciências Sociais Unisinos, 47(1), 3-14. doi: 10.4013/1040.

Chaui, M. d. S. (2001). Escritos sobre a universidade. São Paulo: Editora Unesp.

Costa, R., \& Miguel, M. (2019). Informação, memória institucional e produção acadêmica: o legado da ufes na web of science (2009-2018). Revista de Gestão e Avaliação Educacional, 1(1), 1-17. doi: 10.5902/2318133839273.

Cristofoletti, E. C., \& Serafim, M. P. (2020). Dimensões metodológicas e analíticas da extensão universitária. Educação E Realidade, 45(1). doi: 10.1590/2175-623690670.

Dias Sobrinho, J. (2015). Universidade fraturada: reflexões sobre conhecimento e responsabilidade social. Avaliação: Revista da Avaliação da Educação Superior, 2(3), 581-601. doi: 10.1590/S1414-40772015000300002.

Elliott, G. (2013). Character and impact of social innovation in higher education. International Journal of Continuing Education and Lifelong Learning, 5(2), 71-84. Recuperado de https://eprints.worc.ac.uk/2187/.

Felipe, A. A. C., \& Gomes, J. F. (2014). A parceria entre ciência da informação e responsabilidade social universitária para fins de inclusão social. RDBCI: Revista Digital de Biblioteconomia e Ciência da Informação, 12(1), 147-163. doi: 10.20396/rdbci.v12i1.1622.

Freire, P. R. N. (1985). The politics of education, culture, power, and liberation. New York: Bergin \& Garvey.

Gadotti, M. (2017). Extensão universitária: para quê? São Paulo: Instituto Paulo Freire. Recuperado de http://www.paulofreire.org/noticias/557-extensao -universitaria-para-que.

Gattai, S., \& Bernardes, M. A. (2013). Papel e responsabilidades da universidade no processo socioeducativo presente em movimentos de economia solidária. Revista de Administração Mackenzie, 14(6), 50-81. Recuperado de https://www.scielo.br/pdf/ram/v14n6/04.pdf.

Gomez, S. d. R. M., Corte, M. G. D., \& Rosso, G. P. (2019). A reforma de córdoba e a educação superior. Revista Internacional de Educação Superior, 5. doi: 10.20396/riesup.v5i0.8653655.

Guareschi, P. A. (2008). Ética e relações sociais entre o existente e o possível. In M. G. C. Jacques \& et al. (Eds.), Relações sociais e ética (p. 6-11). Rio de Janeiro: Centro Edelstein de Pesquisas Sociais. Recuperado de http://books .scielo.org/id/6j3gx/pdf/jacques-9788599662892-03.pdf.

Jambeiro, O. (1999). A obrigação de interagir: universidade, empresa, governo. In Integração universidade e empresa ii (p. 18-21). Brasília: IBICT.

Lacan, J. (1966). La science et la vérité $\mathcal{E}$ intervention sur le transfert, in écrits. Paris: Seuil.

Maciel, E. L. N., Melo, D. C. F., Delcarro, J. C. S., Robaina, I. M. M., Jabor, P. M., Goncalves Junior, E., \& Zandonade, E. (2020). Pessoas com deficiência e covid-19 no estado do espírito santo: entre a invisibilidade e a falta de políticas públicas. SciELO Preprints Collection. doi: 10.1590/SciELOPreprints.1540.

Madruga, S. W. (2020). Editorial. Expressa Extensão,
25(2). doi: 10.15210/EE.V25I2.18671

Oliveira, C. V. N. C., Tosta, M. C. R., \& Freitas, R. R. (2020). Curricularization of university extension: a bibliometric analysis. Brazilian Journal of Production Engineering, 6(2), 114-127. Recuperado de https://periodicos.ufes.br/ bjpe/article/view/30835.

Programa de Pós-Graduação em Política Social da Ufes. (2020). Ações de proteção à primeira inf ância ante o covid-19. portal covid-19 nota dos pesquisadores em política social da ufes. Recuperado de http://www.politicasocial.ufes.br/pt-br/conteudo/covid -19-nota-dos-pesquisadores-em-politica-social-da-ufes

Rede Nacional de Extensão. (2020). Ações de extensão da ufes no enfrentamento à pandemia de covid-19. Belo Horizonte: RENEX. Recuperado em 2020, abr. 09, de https://www.ufmg.br/proex/renex/index.php/ renex/202-acoes-de-extensao-da-Ufes-no-enfrentamento-a -pandemia-de-covid-19.

Rosa, G. A. d., \& Trevisan, A. L. (2016). Filosofia da tecnologia e educação: conservação ou crítica inovadora da modernidade? Avaliação: Revista da Avaliação da Educação Superior, 21(3), 719-738. doi: 10.1590/S141440772016000300004.

Sales, C. M. M., Silva, A. I. d., \& Maciel, E. L. N. (2020). Vigilância em saúde da covid-19 no brasil: investigação de contatos pela atenção primária em saúde como estratégia de proteção comunitária. Epidemiologia e Serviços de Saúde, 29(4). doi: 10.5123/s1679-49742020000400011.

Santos, B. S. (2004). A universidade no século xxi: para uma reforma democrática e emancipatória da universidade. São Paulo: Cortez Editora.

Silva. (2017). A responsabilidade social da biblioteconomia nas ações de extensão universitária. Ponto de Acesso, 12(1), 123-124. Recuperado de https://eprints.worc.ac.uk/2187/.

Silva, \& Deboçã, L. (2018). Avaliando as práticas extensionistas na universidade federal de viçosa campus rio paranaíba: das diretrizes do forproex às percepções de atores envolvidos. Revista Gestão Universitária na América Latina, 11 (1). doi: 10.5007/1983-4535.2018v11n1p116.

Soares, M., \& Severino, A. J. (2018). A prática da pesquisa no ensino superior: conhecimento pertencente na formação humana. Avaliação: Revista da Avaliação da Educação Superior, 23(2), 372-390. doi: 10.1590/s141440772018000200006

Thiry-Cherques, H. R. (2020). Responsabilidade moral e identidade empresarial. Revista de Administração Contemporânea, 7(esp), 31-50. Recuperado de https://www.scielo.br/ $\mathrm{pdf} / \mathrm{rac} / \mathrm{v} 7 \mathrm{nspe} / \mathrm{v} 7 \mathrm{nespa03.pdf}$

Tosta, K. C. B. T., Spanhol, F. J., \& Tosta, H. T. (2016). Conhecimento, universidade e inovação: como se relacionam na geração de inovação baseada em conhecimento. Revista Gestão Universitária na América Latina, 9 (3), 245-268. doi: 10.5007/1983-4535.2016v9n3p245.

Universidade Federal do Espírito Santo. Portal Coronavirus. (2020). Pesquisadores da pós-graduação em política social elaboram propostas para período de pandemia. Vitória: Ufes. Recuperado de http://portal.ufes.br/ conteudo/pesquisadores-de-pos-graduacao-em-politica -social-elaboram-propostas-para-periodo-de.

Universidade Federal do Espírito Santo. Pró-reitoria de Extensão. (2020a). Ações de extensão da ufes no enfrentamento à pandemia de covid-19. Vitória: Ufes. Recuperado de https://proex.ufes.br/conteudo/acoes-de-extensao 
-da-ufes-no-enfrentamento-pandemia-de-covid-19\#: :

text $=$ Além $\% 20$ de $\% 20$ integrar $\% 20 a \%$ 20Rede,educaç $\sim$ ao $\%$ 20cient $\%$ C3\% ADfica $\% 2$ C $\% 20$ cultura $\% 20$ e $\% 20$ arte

Universidade Federal do Espírito Santo. Pró-reitoria de Extensão. (2020b). Solidariedade digital. Vitória: Ufes. Recuperado de http://proex.Ufes.br/solidariedade-digital.

Visotsky, J. (2020). La perspectiva de derechos de los pueblos, la perspectiva interseccional y la integralidad de las prácticas, como ejes para la formación de grado y postgrado en las universidades. Praxis Educativa, 24(1), 1-15. doi: 10.19137/praxiseducativa-2020-240107.

Como citar este artigo (APA):

Miguel, M. C., Silveira, R. Z. da, \& Del Maestro, M. L. K. (2021). Extensão universitária no enfrentamento da Covid-19: a universidade e o (re)configurar de projetos e ações. AtoZ: novas práticas em informação e conhecimento, 10(1), 72 - 84. Recuperado de: http://dx.doi.org/10.5380/atoz.v10i1.76152 